\title{
Taxonomia das diretrizes para educação nos planos de governo dos elegíveis à Presidência da República Brasileira (2018)
}

A taxonomy of educational guidelines in the governing plans of candidates to the Presidency of the Brazilian Republic (2018)

\section{Introdução}

Pesquisas sobre a educação básica brasileira têm apontado nos anos recentes avanços em alguns aspectos em nível nacional. Por exemplo, dados do Sistema de Avaliação da Educação Básica (Saeb) indicam que a questão da permanência nos ensinos fundamental e médio é, contemporaneamente, um problema tênue, se comparado ao início da década de 1990. Da mesma forma, as informações recentes do Exame Nacional de Desempenho de Estudantes (Enade) mostram que houve aumento na porcentagem de alunos negros nos cursos de graduação e pós-graduação. Ainda assim, as defasagens entre alunos e instituições de ensino são situações recorrentes e relevantes dentro das unidades educacionais. Os reflexos dessas desigualdades perpassam a Educação Básica (Infantil,

\footnotetext{
Mestrando no Programa de Pós-Graduação em Economia e Desenvolvimento (PPGE\&D) da Universidade Federal de Santa Maria (UFSM), Santa Maria, RS, Brasil. E-mail: <lzr.cezar@gmail.com>

2 Professora no Programa de Pós-Graduação em Economia e Desenvolvimento (PPGE\&D) da Universidade Federal de Santa Maria (UFSM), Santa Maria, RS, Brasil. E-mail: <sibele_oliveira@yahoo.com.br>

3 Professora no Programa de Pós-Graduação em Economia e Desenvolvimento (PPGE\&D) da Universidade Federal de Santa Maria (UFSM), Santa Maria, RS, Brasil. E-mail: <rita.pauli@gmail.com>

4 Agradecemos aos(às) pareceristas anônimos(as) e às editoras da Revista Brasileira de Ciência Política por suas contribuições.
} 
Fundamental, Ensino Médio), sendo também recorrentes nos níveis técnico-profissional e superior. Com o intuito de atenuar tais assimetrias, estudiosos e propositores de políticas públicas nacionais e internacionais vêm promovendo esforços com o objetivo de trazer contribuições e soluções que possam ser incorporadas nos modelos de ensino do país.

Ao longo das últimas décadas, modelos de gestão participativa vêm sendo desenhados e desempenhados dentro do arcabouço institucional brasileiro, seja por meio de conselhos municipais, estaduais e nacionais, seja por meio de modelos escolares de maior cooperação da comunidade nas unidades de ensino. Esse cenário representa um avanço histórico para o país, já que as defasagens na educação pública representam problema de interesse social. Os esforços recentes na criação de programas de governo, como Prouni, Reuni, SISU e Pronatec ${ }^{5}$, permitiram o aumento de vagas nos estágios técnico-profissionalizante e superior e trataram de combater desigualdades sociais de acesso e permanência de alunos de background vulnerável ou provenientes de famílias que vivenciam “inadequação de renda” (SEN, 2013).

Em diferentes níveis, as políticas públicas buscam atender demandas e equilibrar crescimento e desenvolvimento econômico através da qualificação de mão de obra técnica e competente, seja na atuação mercadológica seja desenvolvendo ciência e tecnologia através de pesquisas acadêmicas ou empresas voltadas à inovação. A partir de um período eleitoral, a eleição dos representantes públicos transforma demandas em decisões, ora por meio dos desdobramentos das diretrizes de governo, ora a partir da elaboração de novas políticas públicas. Ademais, a política cria uma ponte entre diferentes espectros sociais e ideológicos, fazendo-se fundamental aos partidos e respectivos candidatos na elaboração de projetos e diretrizes, a partir da legislação de novas leis na figura do Congresso Nacional e/ou na execução por parte do Poder Executivo Federal.

5 Programa Universidade para Todos, Programa de Apoio a Planos de Reestruturação e Expansão das Universidades Federais, Sistema de Seleção Unificada e Programa Nacional de Acesso ao Ensino Técnico e Emprego, respectivamente. 
Os principais atores envolvidos no período eleitoral de 2018 foram os eleitores, que, pelo voto único e secreto, depositaram sua intenção à determinada legenda; e os candidatos, que pleitearam diferentes cargos executivos ou legislativos na Câmara dos Deputados, no Senado e, no caso do presidente eleito, no Palácio da Alvorada.

Partindo da hipótese de que as novas configurações do modus operandi da política brasileira têm esvaziado os programas de governo de conteúdo técnico, e inflado a disputa eleitoral de proposições vazias e sem muitas alternativas de solução, busca-se responder o seguinte problema de pesquisa: os presidenciáveis nas eleições brasileiras de 2018 pautaram seus planos e/ou diretrizes de governo para educação em conteúdo técnico ou político? Tais proposições foram disponibilizadas aos eleitores, jornalistas, partidos da oposição, entre outros, ao longo da campanha eleitoral e sinalizam o perfil das ações do candidato, caso eleito. Cabe esclarecer que, de acordo com dados da Justiça Eleitoral, os cinco candidatos [homens] que contabilizaram 95,04\% dos votos válidos no primeiro turno em 2018 foram: Jair Bolsonaro (Partido Social Liberal - PSL; 46,03\%), Fernando Haddad (Partido dos Trabalhadores - PT; 29,28\%), Ciro Gomes (Partido Democrático Trabalhista - PDT; 12,47\%), Geraldo Alckmin (Partido da Social Democracia Brasileira-PSDB; 4,76\%), João Amoedo (Partido Novo, Novo; 2,5\%). Disputaram o segundo turno os candidatos do PSL e PT.

$\mathrm{O}$ artigo é dividido em quatro seções para além desta introdução, e a próxima conceitua Estado, políticas públicas e agenda, instituições entendidas pelos autores deste ensaio como fundamentais às economias em desenvolvimento, apresenta a tipologia proposta por Bozeman e Pandey (2004) e expõe a teoria que alicerça a análise de conteúdo empreendida. Os procedimentos metodológicos adotados, bem como a teoria dos conjuntos fuzzy, que refina e expande a lógica booleana, são explicitados na terceira seção. As diretrizes dos candidatos mais votados são analisadas na quarta seção. Ao final, apresentam-se alguns comentários e observações, concluindo-se o artigo. 


\section{Fundamentos teóricos}

\section{Estado, agenda e políticas públicas}

Com o principal intuito de retratar o atual panorama das instituições participativas no Brasil, Lopez e Pires (2010) salientam a promulgação da Constituição de 1988 como uma mudança positiva e virtuosa para a dinâmica entre sociedade e Estado. Arquiteta-se aqui a definição de Estado a partir de uma complexidade institucional capaz de estruturar a natureza e os resultados dos conflitos entre grupos (HALL; TAYLOR, 2003). A definição dos autores, fruto da vertente de pesquisa neoinstitucionalismo histórico, traduz tecnicamente o que o período eleitoral geralmente representa para boa parte das democracias contemporâneas. Em Veblen (1912/1983), instituições caracterizam-se como normas de comportamento, convenções e códigos de conduta autoimpostos, respaldadas pelo contexto social ao qual os atores econômicos estão inseridos.

A partir da leitura de Baumgartner e Jones (1993), caracterizamos as eleições de 2018 como um momento de ruptura do ponto de vista de problemas públicos prioritários, ainda como reflexo da crise mundial pós 2008/2009 e da crise política brasileira, que tem culminado desde 2013 em diversas manifestações. Agendas como combate à corrupção e foco em segurança pública foram temas muito discutidos ao longo das campanhas presidenciais, por meio de entrevistas e debates em TV aberta. Essa janela de oportunidade (policy window) cria espaço para que reformas estruturais e novos temas sejam incorporados ao debate e incluídos no campo das políticas públicas (KINGDON, 2006).

Em Secchi (2014, p. 5), “o que define se uma política é ou não pública é a sua intenção de responder a um problema público, e não se o tomador de decisão tem personalidade jurídica estatal ou não estatal". Um problema poderá ou não ser incluído na agenda e, devidamente solucionado, a depender da ação e participação de agentes econômicos e sociais (LOPEZ; PIRES, 2010; GOMIDE; PIRES, 2014). Junto aos atores estatais e representantes políticos propriamente 
ditos, organizações não governamentais (ONGs), entidades privadas e outras instituições podem aliar-se ao governo e formar redes de políticas públicas (policy networks). Os interesses dos políticos e parte das demandas nacionais no período far-se-ão importantes.

A omissão de alguma demanda pública caracteriza a exclusão desse problema da agenda formal ${ }^{6}$ (DYE, 1984; SECCHI, 2014). Por exemplo, para parte dos especialistas, a implementação de uma renda mínima paga pelo Estado brasileiro é variável necessária ao combate à inadequação de renda e a outras desigualdades associadas. O nível estruturador das diretrizes (policy studies) também caracteriza as políticas públicas, de forma a comportar a formulação das diretrizes dos governos (SECCHI, 2014). As políticas públicas são usualmente implementadas de duas formas: top-down e bottom-up, sendo a primeira menos participativa no que tange à inclusão dos agentes sociais do que a segunda (SABATIER; WEIBLE, 1999).

Lopez e Pires (2010) e Pires e Gomide (2014) ressaltam que a inclusão de uma agenda mais participativa por parte dos eventuais elegíveis teria o intuito de evidenciar a preocupação destes com uma agenda transparentemente participativa e democrática. A participação popular é entendida como intrínseca e necessária à efetiva legitimação democrática (FURTADO, 1961; CARDOSO; FALETTO, 1979; FURTADO; 1978; SEN, 2013). Entende-se como agenda "a lista de temas ou problemas que são alvo em dado momento de séria atenção, tanto da parte das autoridades governamentais como de pessoas fora do governo, mas estreitamente associadas às autoridades" (KINGDON, 2006, p. 222).

Do ponto de vista teórico, o presente estudo abarca principalmente os ciclos iniciais das políticas públicas (RAEDER, 2014; SECCHI, 2014), a saber: identificação do problema; formulação de agenda; formulação de alternativas; tomada de decisão ${ }^{7}$; implementação; avaliação e extinção. Compreende-se a formulação de alternativas

6 A análise das agendas dos candidatos não eleitos é respaldada por argumentos apresentados em Bachrach e Baratz (1962), Dye (1984) e Souza (2006). Conhecer as proposições preteridas pelos eleitores é tão relevante quanto analisar as elegidas.

7 Bachrach e Baratz (2011) sugerem a importância da não tomada de decisões, embora reconheçam a dificuldade de mensuração dessas entrelinhas do poder. 
como uma etapa subsidiada por conhecimento técnico ${ }^{8}$, sendo que as diretrizes - que explicitam tal caminho - alocam-se na tipologia proposta como eminentemente técnicas. Entretanto, Secchi (2014) alerta para o fato de que o ciclo é dinâmico e complexo, partindo do princípio de que algumas fases são transversais e, eventualmente, realizadas durante todo o ciclo. É o caso, por exemplo, da avaliação. $\mathrm{O}$ autor adverte que alguns estudiosos desconsideram o ciclo e tratam das políticas públicas como um único processo em sua diversidade de nuances. Uma introdução à teoria a qual tipifica o conteúdo em político e técnico é apresentada a seguir (SECCHI, 2014).

\section{A tipologia de Bozeman e Pandey (2004)}

É recorrente e atual a tipologia apresentada, que faz referência à importância dos conhecimentos técnico e prático para a formulação de políticas públicas; para que não se faça uma "política sem sentido, aquela elaborada sem conhecimento específico sobre o problema ou sem alternativas de solução para o problema, além de ser vazia de intenções políticas genuínas" (SECCHI, 2014, p. 22). Secchi (2014) argumenta que a adoção de uma tipologia pode acarretar reducionismo, mas, por outro lado, possibilita que a informação seja traduzida de modo a estabelecer um diálogo com a população, pesquisadores, propositores e analistas de políticas públicas. A eficácia da política pública é variável explicada, entre outros fatores, pela capacidade técnica e por objetivos bem definidos. Uma limitação dessa análise, reconhecida pelos próprios autores, e destacada em Muzzi (2014), está na alteração do caráter das políticas ao longo de suas várias etapas. Em Secchi (2014, p. 31):

[...] uma das dificuldades da tipologia de Bozeman e Pandey é que políticas públicas podem ser alteradas em essência ao longo do ciclo de política pública. Uma política pode por

8 Autores explicam que a relação entre desenvolvimento e instituições deve ater-se aos arranjos de políticas específicas, contando com a presença de componentes técnico-administrativo (gestão governamental) e políticos (responsáveis pela negociação burocrática entre Executivo e demais agentes) (GOMIDE; PIRES, 2014). 
exemplo, parecer eminentemente técnica da fase de estudo de alternativas, mas se revelar fortemente política no momento da tomada de decisão.

Bozeman e Pandey $(2004)^{9}$ reconhecem a distinção de conteúdo técnico e político como um complemento aos estudos clássicos realizados pela literatura especializada que envolve as abordagens sobre políticas públicas. Logo, parte-se da premissa que conteúdos técnicos são decisivos na formação de agenda do presidente eleito. A taxonomia ${ }^{10}$, proposta por este estudo, pretende mapear tanto políticas de governo - ações imediatas do grupo político - quanto políticas de Estado, medidas estruturais, de longo prazo; tão necessárias e, por vezes, negligenciadas. A proposta principal é colaborar na construção de um modelo conceitual que possa avaliar diferentes graus de vieses eminentemente técnicos ou políticos nas diretrizes de governo apresentadas por elegíveis à população.

Decisões políticas mais técnicas envolvem: maior racionalidade econômica, configuradas na formação de uma equipe técnica especializada. No caso das políticas, é esperado um grupo maior de agentes externos e níveis mais altos de conflito, já que dariam maior peso relativo aos fins e não aos meios. Essa ressalva se torna patente no argumento de que as decisões circulam entre duas âncoras na qual os conteúdos "eminentemente técnico[s] ou político[s]" encontram-se nas extremidades opostas ${ }^{11}$ (BOZEMAN; PANDEY, 2004). A análise apresentada pelos autores pode ser resumida em quatro hipóteses:

a) Hipótese 1 (Critério de decisão): (i) as decisões políticas tendem a basear-se em critérios de custo-efetividade e justiça

9 Bozeman e Pandey (2004) citam: Allison (1971 apud BOZEMAN; PANDEY, 2004), Lindblom (1959 apud BOZEMAN; PANDEY, 2004), Pfeffer (1981 apud BOZEMAN; PANDEY, 2004) e Thompson (1967 apud BOZEMAN; PANDEY, 2004).

10 Para Edler e Georghiou (2007), taxonomias são como fotografias da realidade e, portanto, não são dinâmicas. A fotografia por nós proposta se mostra promissora na avaliação de diretrizes de governo em diferentes instâncias (municipal, estadual, federal), podendo ser adaptada para outros recortes temáticos (saúde, emprego etc.).

11 Os autores reconhecem a inexistência de uma decisão técnica do tipo puro ou política do tipo puro. Eventualmente, as decisões técnicas podem "politizar-se" (BOZEMAN; PANDEY, 2004). 
social; e (ii) as decisões técnicas em critérios de custo-efetividade, viabilidade técnica e utilidade.

b) Hipótese 2 (Tempo de decisão): (i) as decisões políticas tendem a exigir menos tempo, são mais propensas a serem vistas como temporárias e menos orientadas à estabilidade; e (ii) as decisões técnicas tendem a exigir mais tempo para implementação, e são mais prováveis de serem estáveis.

c) Hipótese 3 (Participantes da decisão): (i) as decisões políticas tendem a incluir mais participantes internos e mais externos, além de uma porcentagem maior de participantes externos; e (ii) as decisões técnicas tendem a incluir menos participantes internos, externos e totais, mas uma porcentagem maior de participantes externos.

d) Hipótese 4 (Qualidade da informação e burocracia): (i) as decisões políticas tendem a ter menor qualidade das informações e níveis mais baixos de burocracia nas decisões; e (ii) as técnicas acabam por ter informações de maior qualidade e níveis mais altos de burocracia.

Ao tratar a sociedade como um ambiente complexo, uma agenda, por mais técnica que pareça, terá de se adaptar e, em alguns momentos, passar por reformulações (AGUM; RISCADO; MENEZES, 2015). Os autores, ao adotarem em suas análises a proposta de modelo incremental de Lindblom (1959), defendem a ideia de que a qualidade do embasamento - que precede o momento de decisão - garantiria maiores chances de sucesso à diretriz formulada.

Os autores da tipologia ainda reforçam a necessidade de realização de estudos que utilizem de análises empíricas na forma: "quase todo trabalho relevante é teórico, com poucos estudos empíricos, se houver algum, comparando diretamente decisões com conteúdo técnico e político" (BOZEMAN; PANDEY, 2004, p. 4, tradução nossa). A taxonomia - proposta e apresentada a seguir - consiste em esforço no sentido de contribuir para o campo das ciências sociais e, eventualmente, garantir transbordamentos futuros na construção de períodos eleitorais envolvidos de mais coerência 
técnica, os quais garantam políticas públicas com maiores chances de sucesso e impactos sociais positivos. A análise de conteúdo, realizada pelos autores da presente pesquisa, viabiliza-se pelo uso do instrumental fuzzy.

\section{Uma introdução à análise de conteúdo}

A análise, como uma técnica de investigação, a partir da descrição de determinado material de comunicação, visa a sistematizar, esquematizar, quantificar, qualificar, a partir de critérios técnicos, certo conteúdo (BARDIN, 1977). As regras devem ser homogêneas, exaustivas no tocante à exploração de todo o material, exclusivas porque um mesmo elemento não poderá participar de duas categorias singulares e distintas e objetivas, para que diferentes analistas ${ }^{12}$ se aproximem de iguais resultados. Como será apresentado na sequência, a abordagem fuzzy contorna e qualifica a questão da exclusividade, atribuindo graus de pertencimento aos conjuntos categóricos. Para a autora, a análise de conteúdo se organiza em

[...] um conjunto de técnicas de análise das comunicações, visando obter, por procedimentos, sistemáticos e objetivos de descrição do conteúdo das mensagens, indicadores (quantitativos ou não) que permitam a inferência de conhecimentos relativos às condições de produção/recepção) variáveis inferidas destas mensagens (BARDIN, 1977, p. 42).

Bardin (1977) argumenta que a análise de conteúdo configura exploração enriquecedora (função heurística), para além de leituras superficiais instantâneas e subjetivas. A determinação de uma matriz de tipificação - como uma ferramenta que facilita a pesquisa, padronizando-a e evitando desvios desnecessários - tem uma segunda função de administração da prova. Os métodos das

12 Moraes (1999) reitera o caráter teórico e prático do método, especialmente no campo das ciências sociais, que pode ser aplicado em diferentes materiais, tais como jornais, informes, livros, entrevistas, planos de governo, entre outros. O autor vai salientar que "de certo modo a análise de conteúdo é uma interpretação pessoal por parte do pesquisador com relação à percepção que tem dos dados. Não é possível uma leitura neutra. Toda leitura se constitui numa interpretação"(MORAES, 1999, p. 3). 
análises de conteúdo podem ser, muitas vezes, intransponíveis, explica a autora. Categoricamente, e consoante Moraes (1999), o presente estudo se volta majoritariamente para a questão 'Para dizer o quê?', direcionando o esforço para o valor informacional, as palavras, os argumentos, as estatísticas e as ideias expressos nas diretrizes de governo.

Conforme Ander-Egg (1978), são três fases: (1) estabelecimento da unidade de análise que, nesse caso, na esteira da tipologia de Bozeman e Pandey (2004), debruça-se sobre os planos de governo para educação dos presidenciáveis, documentos disponibilizados e disponíveis no site do Tribunal Superior Eleitoral (TSE); (2) determinação das categorias de análise (categorias temáticas), que seguirão os critérios mencionados nas quatro hipóteses: (i) Critério de decisão; (ii) Tempo de decisão; (iii) Participantes da decisão; e (iv) Qualidade da informação e burocracia; e (3) seleção da amostra do material de análise. Opta-se pelo recorte dos cinco candidatos mais votados, conforme resultados obtidos em primeiro turno eleitoral.

\section{O fenômeno eleitoral e as nuances das diretrizes de governo}

Para o período eleitoral de 2010, Nicolau (2014) avalia o efeito de variáveis do banco de dados do Estudo Eleitoral Brasileiro (Eseb) na propensão de cidadãos votarem nos presidenciáveis Dilma Rousseff, José Serra e Marina Silva. Ceteris paribus, entre os principais resultados, destaca-se: (i) morar no Nordeste configurou fator que aumentou a probabilidade de voto em Rousseff e diminuiu a chance de voto em Serra, comparativamente. Para a região sul, o oposto ocorre: (ii) a identificação com a esquerda aumentou as chances de votos em Dilma, no entanto, no tocante à variável escolaridade, essa probabilidade caía à medida que a faixa de escolaridade aumentava. Para Marina Silva, as chances aumentavam com a escolaridade. E ainda (iii) a religião também se mostrou variável decisiva, pois, entre os evangélicos, as chances de se votar em Dilma foram menores quando comparadas às de Marina -cenário igualmente observado em 2014. Amaral e Ribeiro (2015) analisam, a partir 
do mesmo banco de dados citado, conquanto para o ano de 2014, nos dois turnos eleitorais, os determinantes do voto. No primeiro turno, o modelo estatístico de regressão logística multinominal dialoga com os resultados expostos para o ano de 2010, ecoando, inclusive, o resultado - não esperado - da ascensão social, e também a participação do Programa Bolsa Família (PBF) não explicar a decisão de voto. Posicionar-se ideologicamente, ainda que em um espectro mais à esquerda, aumentaram as chances de voto em Aécio Neves. No contexto do segundo turno, a técnica de regressão logística binária atrela maior probabilidade de escolha ao Aécio quando o entrevistado se autolocaliza à direita, gostando do PSDB e não tendo votado em Dilma no segundo turno de 2010. Integrar a política pública $\mathrm{PBF}$, no caso do segundo turno, mostrou-se variável estatisticamente significativa, privilegiando a candidata petista, o que, porém, torna esse efeito não conclusivo e acaba por reavivar o debate acerca do tema.

Ao investigarem o período compreendido entre 16 de agosto e 28 de outubro de 2018, Mont'Alverne e Mitozo (2019) analisaram o conteúdo disseminado pelos espaços de comunicação, em especial a maneira pela qual se organizou o fluxo de informações no WhatsApp. O principal canal de informações compartilhado nos 213 grupos públicos foi a plataforma de vídeos YouTube, em segundo lugar o Facebook. As autoras ressaltam a tímida participação de sites ou portais jornalísticos tradicionais frente aos canais já citados, relatando preocupação no que concerne à presença de desinformação (disinformation) e de informação despropositadamente errada (misinformation) em períodos e espaços de disputa.

Notável tem sido o esforço dos acadêmicos e pesquisadores em se debruçarem sobre os períodos eleitorais, investigando perfil e preferência dos eleitores nos processos decisórios, entre outros objetos. Os autores citados destacam e resgatam o caráter complexo, retrospectivo e memorial do comportamento eleitoral (NICOLAU, 2014; AMARAL; RIBEIRO, 2015; MONT'ALVERNE; MITOZO, 2019). É possível notar, entretanto, uma lacuna no tocante à avaliação mais atenta dos materiais de campanha dos presidenciáveis, na esteira 
de identificar sutilezas e padrões dos conteúdos apresentados pelos candidatos e legendas, reiterando o caráter multidimensional das eleições e a importância das informações e da imprensa às democracias.

\section{Metodologia}

\section{As potencialidades dos sistemas de inferência fuzzy}

Segundo Benini (2012), a teoria dos conjuntos fuzzy faz-se de grande utilidade para a explicação de fenômenos sociais, que dificilmente seriam passíveis de modelização matemática precisa, partindo dos pressupostos de racionalidade limitada dos agentes e incertezas presentes em momentos de decisões e escolhas (ANDRADE, 2011). Para compreender fenômenos econômicos e sociais, trata-se de um ferramental de extrema validade, especialmente nos casos de tratamento da complexidade, já que permite "modelar o raciocínio humano, que é aproximado e parcial em sua essência" (BENINI, 2012, p. 4).

A lógica fuzzy, propalada por Zadeh (1965), configura uma opção para representar matematicamente fenômenos econômicos/ sociais, capaz de captar nuances contidas nos intervalos "não inteiros" por meio da geração de índices com base em dada coleção de entradas. A noção nebulosa estende a premissa clássica da abordagem booleana, que identifica valores em um espectro de intervalo fechado [0;1]. Ragin e Pennings (2005) elencam uma série de argumentos que justificam o emprego de ferramental fuzzy ao entendimento dos fenômenos socioeconômicos. Esclarece-se que seja $\mathrm{U}$ um conjunto universo não vazio $(\mathrm{U}=\varnothing)$, um conjunto $f u z z y$ $A$ em $U$ é caracterizado por sua função de pertinência:

$$
\begin{aligned}
& \mu_{\mathrm{A}}: U \rightarrow[0,1] \\
& \mathrm{x} \rightarrow \mu_{\mathrm{A}}^{(\mathrm{x})}
\end{aligned}
$$

Sendo $\mu_{\mathrm{A})}(\mathrm{x})$ interpretado como o grau de pertinência do elemento $x$ no conjunto fuzzy $A$ para cada $\mathrm{x} \in \mathrm{U}$. Assim, nos conjuntos fuzzy, o fator de pertinência pode admitir qualquer valor entre 0 e 1, de forma que o valor 0 sugere a completa exclusão ao 
conjunto e o valor 1 representa completa pertinência de determinado elemento ao conjunto (GOMIDE; GUDWIN, 1994). Por meio da manipulação fuzzy, é possível representar conceitos qualitativos de forma quantitativa (e vice-versa). Para tanto, operam-se variáveis linguísticas, que se caracterizam assumindo valores dentro de um conjunto de termos linguísticos, isto é, "palavras ou frases" (GOMIDE; GUDWIN, 1994).

Ortega (2001) explica que os termos linguísticos são empregados para expressar conceitos e conhecimentos na comunicação humana, sendo, em muitas ocasiões, a única maneira de quantificar os dados/informações. O uso de variáveis linguísticas é capaz de capturar "valores" ou "sentidos" dentro de intervalos não necessariamente inteiros, como, por exemplo, "alto", "médio", "baixo". $\mathrm{Na}$ abordagem fuzzy, um elemento pode pertencer parcialmente, conforme função de pertinência (ZADEH, 1965). Portanto, ao nos referirmos ao "conteúdo eminentemente técnico" ou "plano de governo vago", utilizamos expressões para qualificar os objetos de análise, de forma a também operar com termos linguísticos.

Ressalta-se também a existência de uma complexa teia de conceitos que formaliza tanto a teoria dos conjuntos quanto a lógica fuzzy, a qual é indispensável ao entendimento acerca do processo de modelagem e controle de sistemas fuzzy (ZADEH, 1965; GOMIDE; GUDWIN, 1994; ORTEGA, 2001; BENINI, 2012). Em suma, os sistemas são compostos das seguintes etapas: fuzzyficação, base de conhecimentos, método de inferência e defuzzyficação.

O processo de fuzzyficação transforma números (valores discretos) em conjuntos fuzzy, de modo a criar variáveis linguísticas. Por sua vez, a base de conhecimento se configura a partir de uma base de regras, em que estão as declarações linguísticas do tipo "se (condição antecedente) ... então (condição consequente)", definidas por especialistas ou retiradas de um conjunto de dados numéricos (ANTUNES, 2006). Segundo Benini (2012, p. 32), na base de dados são expressos "as variáveis linguísticas, as definições dos respectivos universos de discursos e o conjunto de funções de pertinências". 
Ainda, a operacionalização de um sistema de inferência fuzzy requer o elenco do método de inferência e a implementação do processo de defuzzyficação. Entre os métodos de inferência mais empregados, destacam-se o Mamdani e o Takagi-Sugeno. No primeiro caso, são utilizados conjuntos fuzzy nos antecedentes e consequentes das regras fuzzy. Já no segundo, os antecedentes são proposições fuzzy e os consequentes são representados por uma função das variáveis de entrada (BENINI, 2012).

\section{Aplicações empíricas do instrumental}

Oliveira, Caires e Oliveira (2017), em “Uma análise exploratória para a identificação de clusters de propensão à criminalidade no estado da Bahia para o ano de 2010", identificaram média vulnerabilidade social para o controlador homônimo, cujos critérios estão relacionados ao Índice de Desenvolvimento Humano Municipal (IDH-M), Coeficiente de Gini e Percentual da População Assistida Social e Previdencialmente. Definidos os controladores "Herança Educacional/Institucional" e "Propensão à Criminalidade", ou seja, a base de regras dos arranjos que comporiam o sistema, o artigo identifica baixa herança educacional e institucional (cultural) familiar, bem como média propensão à criminalidade.

Oliveira et. al. (2018), com uso de dados primários coletados nos bairros KM3 e Presidente João Goulart no município de Santa Maria-RS, criaram um indicador para a representação do fenômeno pobreza multidimensional. $\mathrm{O}$ estudo inferiu situação de privação ao acesso a serviços de saúde, desde atendimento odontológico até maus serviços prestados nas unidades de bairro. Para as condições de habitação, o resultado apontou para relativo conforto e bem-estar da população entrevistada. Os resultados para o conjunto fuzzy desenhado diagnosticaram nesses bairros de baixa a média pobreza, associada principalmente aos quesitos saúde, como mencionamos, e, em menor nível, a trabalho, renda e educação.

Em um estudo aplicado ao Rio Grande do Sul (RS) e com base em intervalos definidos a partir do percentual de nascimentos por faixas de renda e de escolaridade, Lazaretti, Teixeira e Oliveira 
(2019) representaram a pobreza multidimensional em três diferentes níveis (Baixa, Média e Alta). A análise apontou que cerca de $80 \%$, ou seja, 413 dos 496 municípios do estado possuem alta vulnerabilidade à pobreza e que 83 pertencem ao conjunto de vulnerabilidade de pobreza média, o que indica um cenário preocupante, dentro de um recorte analítico que busca representar a inadequação de renda associada a outras variáveis qualitativas e relevantes em análises desse tema (SEN, 2013).

Santos, Oliveira e Dias (2020) utilizam o instrumental para analisar o grau de aderência às políticas de ações afirmativas no Brasil, à luz do pilar cognitivo das instituições proposto por William Scott. O Índice de Aceitação Potencial da Política de Ações Afirmativas, construído com informações do Exame de Desempenho do Estudante de 2017, com base no perfil de renda dos estudantes ingressantes via ações afirmativas raciais, no tempo de duração da graduação desses estudantes e baseado em seus desempenhos, identifica um alto potencial para o recorte pleiteado. Conquanto, os autores ressaltam que, apesar dos resultados otimistas em termos do potencial de aceitação, complexidades culturais, sociais e institucionais brasileiras inviabilizam a ponte entre os resultados do indicador e o pilar cognitivo da parcela da população contrária às ações afirmativas.

\section{Taxonomia para análise das diretrizes governamentais}

O sistema proposto se organiza em 81 regras fuzzy, sendo composto de quatro variáveis de entrada e uma variável de saída (Figura 1). Entre as variáveis de entrada (inputs), que têm a função de balizar a especificação dos planos em nossa taxonomia, citam-se: Burocracia e Robustez Informacional; Viabilidade Técnica; Estratégia de Governo; Gestão Participativa e Democrática. A variável de saída é intitulada Taxonomia do Plano de Governo. 
Figura 1 - Sistema fuzzy para análise das diretrizes de governo para educação

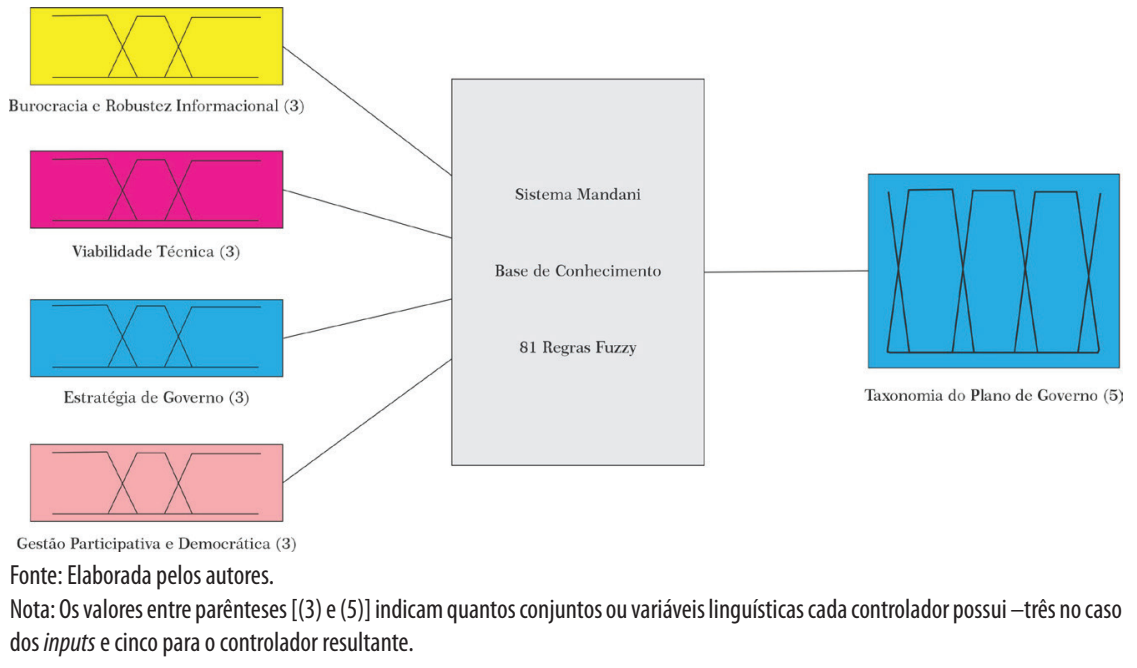

A variável de entrada Burocracia e Robustez Informacional está associada à qualidade técnica do plano de governo, em termos de indicadores e estatísticas para os seguintes níveis: básico (Educação Infantil, Fundamental e Médio), técnico e inclusivo, e superior. Busca qualificar também o conteúdo, conforme o grau de importância atribuído à burocracia ${ }^{13}$ no processo de gestão governamental -à medida que reconheça as capacidades burocráticas como fator necessário (mas não suficiente) ao governo, o plano é classificado como mais técnico ${ }^{14}$. Assim sendo, para a sua construção, foi operacionalizado um sistema de inferência próprio, no qual os conteúdos que demonstraram aversão ao aparato burocrático foram qualificados no âmbito de um viés político ${ }^{15}$.

13 Burocracia, segundo Weber, Gerth e Mills (1958), constitui-se na organização de um aparato técnicoadministrativo, de profissionais especializados, selecionados de acordo com critérios racionais, encarregados de múltiplas tarefas importantes dentro do sistema.

14 Do ponto de vista teórico, as capacidades estatais configuram ordenação dos processos de organização e arranjo estatais ligados à governabilidade e autonomia (HUNTINGTON, 1968).

15 O subsistema fuzzy Burocracia e Robustez Governamental foi obtido por meio da operação de um sistema Mamdani, com duas variáveis de entrada ('Burocracia' e 'Robustez Governamental'), uma variável de saída nove regras fuzzy. 
Para definição da variável de entrada Viabilidade Técnica, leva-se em conta a natureza do conteúdo dos planos de governo e se avaliam: (i) a presença de forte apelo à justiça social nas sentenças e argumentos apresentados; e, (ii) as características de viabilidade técnica e utilidade, traduzidas neste trabalho como metas claras e estabelecidas para correção de assimetrias educacionais existentes no país. Como critério de decisão, adotam-se as premissas de eficácia e equidade educacional $^{16}$ (MORTIMORE, 1991; BROOKE; SOARES, 2008; ALVES; FRANCO, 2008; SOARES; DELGADO, 2016).

A delimitação da variável de entrada Estratégia de Governo faz referência ao tempo de decisão prevista para a consolidação das ações em educação nos planos de governo dos elegíveis. Classifica-se o conteúdo como técnico se este privilegia a educação e o conhecimento como constituinte de um projeto de desenvolvimento de longo prazo $^{17}$ (FURTADO, 1961; EVANS, 1995; BRESSER-PEREIRA, 2006; FONSECA, 2015) - para além do papel tradicional das escolas e das universidades de formação profissional -, projeto que possa implicar uma melhora do bem-estar da população (HAUSMAN; McPHERSON, 2006). Não se pretende atribuir demérito aos programas que cumprem a função tradicional pensada para o curto prazo, aqui já mencionada, mas, conforme a literatura sugere, países que hoje desempenham papel ativo em indústrias de tecnologia de ponta, adotaram, no século passado, arcabouço institucional e educacional voltado em capacitações e qualificação a curto, médio e longo prazo que - por fim - pudesse constituir um Sistema Nacional de Inovação (EVANS, 1995; FREEMAN, 1995; CASSIOLATO, 1999; ZUCOLOTO, 2010; VONA; CONSOLI, 2014; GARCIA, 2017).

16 Para Mortimore (1991), a eficácia escolar diz respeito às unidades de ensino que proporcionam ao aluno um resultado além do esperado, levando em conta o grupo discente, sua origem e composição social.

17 O Estado Liberal (século XIX) surge no intuito de garantir os direitos civis e as liberdades, e tem papel chave no desenvolvimento econômico. A partir de contribuições de Souza (2004 apud BRESSER-PEREIRA, 2006), Bresser-Pereira (2006) explica que o governo deve criar instrumentos de emancipação social, ao equilibrar crescimento econômico e distribuição de renda, promovendo igualdade social, cidadania, direitos individuais e coletivos. 
A variável de entrada Gestão Participativa e Democrática está associada ao perfil do papel esperado dos atores sociais nos planos de governo, engessado na participação e democratização dos ambientes de ensino e pesquisa. A análise de conteúdo realizada nas diretrizes busca identificar projetos que pleiteariam investir nos atores cotidianos da educação (professores, pais, alunos, técnicos-administrativos), mas que também valorizam os espaços públicos de educação e pesquisa, como um recinto a que a comunidade possa ocupar, de forma participativa, integrada, extensiva (MORAES; RUIZ, 2017; LOPEZ; PIRES, 2010; GATTI, 2010). Caracteriza conteúdo eminentemente político aquele que reconhece a presença, mas não atribui peso à atuação de atores externos aos centros educacionais e universidades. $\mathrm{O}$ eminentemente técnico prevê importância e protagonismo dos agentes.

A Tabela 1 apresenta os universos de discurso para cada uma das variáveis acima descritas, bem como os parâmetros empregados na caracterização de cada um dos conjuntos fuzzy que os constituem.

Tabela 1 - Especificação das variáveis de entrada e saída do sistema fuzzy

\begin{tabular}{|c|c|c|c|}
\hline Variáveis de entrada & Universo de discurso & Termos linguísticos & Parâmetros \\
\hline \multirow{3}{*}{ Viabilidade Técnica } & \multirow{3}{*}[0,100]{} & Baixa & {$[002535]$} \\
\hline & & Moderada & [25356575] \\
\hline & & Alta & [65 655100100$]$ \\
\hline \multirow{3}{*}{ Estratégia de Governo } & \multirow{3}{*}[0,30]{} & Curto Prazo & [00812] \\
\hline & & Médio Prazo & [8 121620$]$ \\
\hline & & Longo Prazo & [16203030] \\
\hline \multirow{3}{*}{ Gestão Participativa e Democrática } & \multirow{3}{*}[0,100]{} & Baixa & {$[002535]$} \\
\hline & & Moderada & [25356575] \\
\hline & & Alta & [65 655100100$]$ \\
\hline \multirow{3}{*}{ Burocracia e Robustez Informacional } & \multirow{3}{*}[0,100]{} & Baixa & [0 002535$]$ \\
\hline & & Moderada & [25356575] \\
\hline & & Alta & [65 655100100$]$ \\
\hline Variável de saída & Universo de discurso & Termos linguísticos & Parâmetros \\
\hline \multirow{5}{*}{ Taxonomia do Plano de Governo } & \multirow{5}{*}[0,100]{} & Eminentemente Político & {$\left[\begin{array}{lll}0 & 0 & 10\end{array}\right]$} \\
\hline & & Mormente Político & [0 1030 40] \\
\hline & & Moderado & [30 40 60 70] \\
\hline & & Mormente Técnico & [607090 100] \\
\hline & & Eminentemente Técnico & [90 100 100] \\
\hline
\end{tabular}

Fonte: Elaborada pelos autores.

Nota: 0 universo de discurso aparece no eixo horizontal das Figuras 2, 3, 4, 5 e 6, pelas quais buscamos representar graficamente as variáveis de entrada "Universo de discurso", "Termos linguísticos" e "Parâmetros" do sistema fuzzy proposto. 
A Figura 2 apresenta os intervalos de pertinência dos conjuntos de saída possíveis, classificando as diretrizes de governo dos candidatos em: (i) eminentemente político; (ii) mormente político; (iii) moderado; (iv) mormente técnico; e $(v)$ eminentemente técnico. Esquematiza a variável de saída Taxonomia do Plano de Governo, com a explicitação de seus conjuntos fuzzy, funções de pertinência e termos linguísticos. O intervalo horizontal está compreendido entre os valores 0 e 100. Ao se aproximar de 0 , o conteúdo caminha para um viés eminentemente político e, tendendo a 100, o viés do conteúdo se faz eminentemente técnico. Esse sistema de inferência permite que um determinado resultado esteja contido em mais de um conjunto, o que faz diferir esse método do tradicional método booleano, no qual o pertencimento se associa a um conjunto "ou" a outro. Metodologicamente, essa limitação é superada, a lógica fuzzy dá um passo adiante.

Figura 2 - Representação gráfica da variável de saída Taxonomia do Plano de Governo

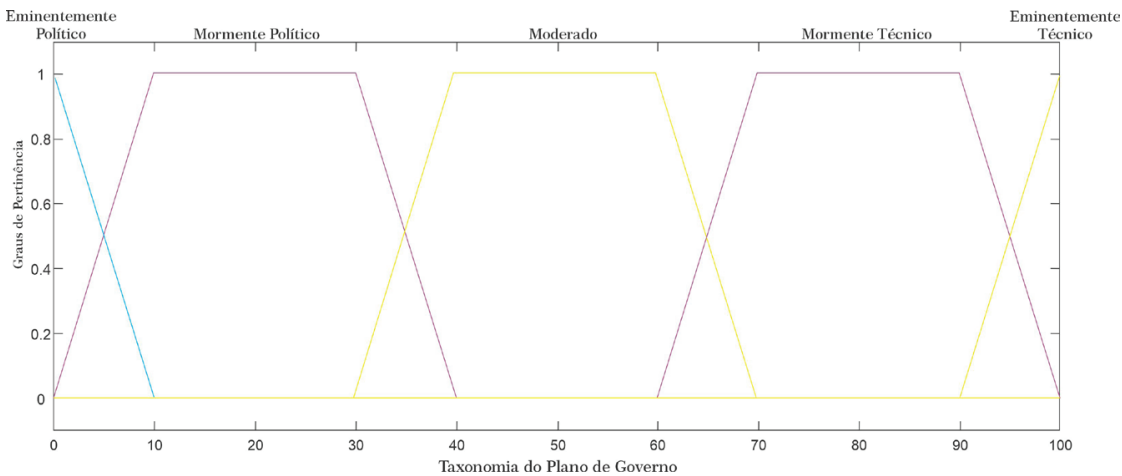

Fonte: Elaborada pelos autores a partir de informações coletadas dos planos de governo analisados.

Nota: Os graus de pertinência (eixo vertical) variam de 0 a 1.0 conteúdo é classificado conforme valor obtido por meio da combinação entre a análise de conteúdo e a operacionalização do sistema estabelecido na Tabela 1. Um exemplo numérico: se um determinado plano de governo, a partir das variáveis de entrada, obtém, como resultante, 0 valor 35, é definido pela Taxonomia do Plano de Governo como Mormente Político e Moderado, ambos com graus de pertinência 0,5.

A seguir, discorre-se sobre os planos dos cinco candidatos mais votados no primeiro turno da eleição presidencial brasileira de 2018, bem como são apresentados os resultados da análise fuzzy. 


\section{Análise das diretrizes de governo para Educação na eleição presidencial brasileira de 2018}

Os planos mencionados foram disponibilizados nos respectivos sites dos candidatos e/ou partidos e amplamente divulgados pelos veículos de comunicação. Os especialistas consultados para a elaboração das diretrizes de educação não aparecem assinalados nos documentos, com exceção de Geraldo Alckmin, que, na seção de Agradecimentos, elenca uma série de profissionais (ALCKMIN, 2018, p. 99). Com base na análise de conteúdo das diretrizes de governo dos elegíveis ao cargo de chefia do Executivo do Brasil, estimaram-se os sistemas fuzzy, dos quais deriva-se a Taxonomia do Plano de Governo, cenário no qual as variáveis que resultaram foram, respectivamente, para Ciro Gomes, Jair Bolsonaro, Fernando Haddad, João Amoedo e Geraldo Alckmin: Burocracia e Robustez informacional $(50 ; 15 ; 85 ; 15 ; 15)$; Viabilidade Técnica $(80 ; 25 ; 90 ; 20 ; 50)$; Estratégia de Governo (15;8;25;8;15); Gestão Participativa e Democrática $(60 ; 20 ; 90 ; 10 ; 30)$.

Os resultados apontaram para as seguintes fotografias: as diretrizes de governo para educação de Jair Bolsonaro e João Amoedo são qualificadas dentro dos conjuntos fuzzy eminentemente político (com grau de pertencimento de 0,7 ) e mormente político (com grau de pertencimento de 0,3). As diretrizes de Geraldo Alckmin estão alocadas com grau de pertencimento 1,0 ao conjunto fuzzy mormente político. O resultado para Ciro Gomes qualifica as suas diretrizes no conjunto fuzzy mormente técnico, com grau de pertencimento 1,0. As diretrizes do candidato Fernando Haddad são classificadas na forma mormente técnico e eminentemente técnico, com grau de pertencimento de 0,2 e 0,8 respectivamente. Na sequência, apresenta-se com maior detalhamento a configuração da base para análise de conteúdo, além das variáveis de entrada e saída de cada um dos planos de governo.

"Mais oportunidades, menos privilégios" traz o slogan do plano de governo de João Amoedo. O partido do candidato foi fundado recentemente, em 2011, e o seu site apresenta essa legenda sob a premissa de um partido político diferente. Sugere, ainda, a defesa de 
"liberdades individuais com responsabilidade", para além da defesa do livre mercado em oposição aos serviços prestados pelo Estado. Apesar de não apresentarem explicitamente uma proposta de longo prazo para Educação em seu Programa, como veremos a seguir, o partido diz acreditar em um projeto de longo prazo de país, que perpasse as eleições e abranja as próximas gerações.

No decorrer das eleições, uma das bandeiras bradadas pelo candidato se associava ao fato de se considerar um outsider (agente externo) no cenário político tradicional. As proposições do candidato são, comparativamente aos demais, as mais genéricas (ou vagas); tal como o Programa mais enxuto, com apenas 23 páginas. "Acesso à educação básica de qualidade, subir o Brasil 50 posições no ranking do PISA, universalizar o acesso das crianças às creches, bolsas em escolas particulares para alunos do ensino público" são algumas das estratégias especificadas no plano. Uma "gestão profissional" das escolas é sugerida, mas não há detalhamento da utilização do termo (AMOEDO, 2018, p. 4-11). Por meio do Fundo de Manutenção e Desenvolvimento da Educação Básica (Fundeb), o plano do partido Novo se propõe a reconhecer e valorizar as escolas que melhorarem o desempenho dos alunos. Tática também descrita no documento apresentado por Bolsonaro, o Ensino Médio-Técnico como estratégia de qualificação para o mercado de trabalho, além do modelo de Hélice Tripla no que se refere às universidades públicas aparecem nas diretrizes de Amoedo. 
Figura 3 - Resultados fuzzy para a variável de entrada Burocracia e Robustez Informacional

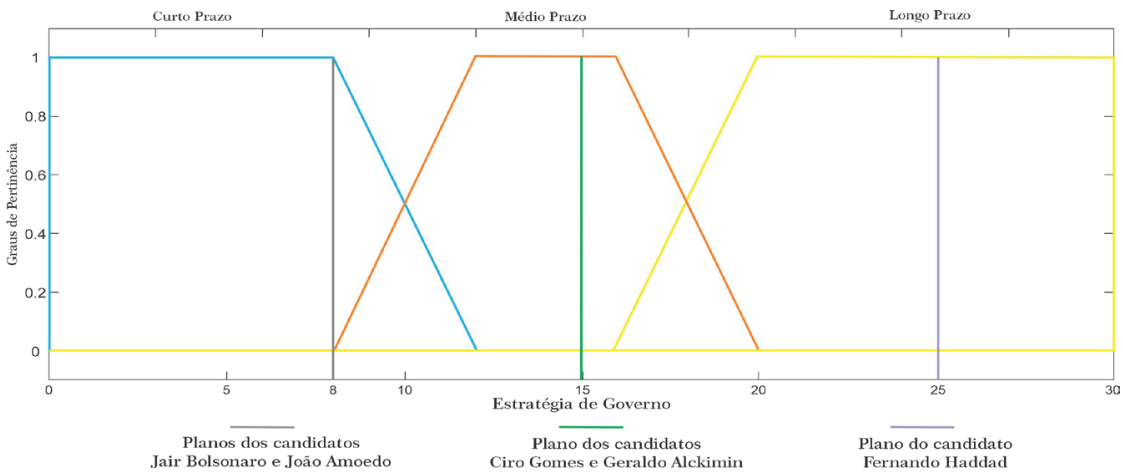

Fonte: Elaborada pelos autores a partir de informações coletadas dos planos de governo analisados.

Nota: No primeiro nível, a análise de conteúdo atribui os seguintes valores para as variáveis de entrada (Burocracia; Robustez informacional): Ciro Gomes (50;4), Jair Bolsonaro (10;4), Fernando Haddad (60;6), João Amoedo (20;3) e Geraldo Alckmin (20;0). Fazendo uso do MATLAB, e para cada um dos respectivos candidatos, obtiveram-se os outputs para o critério Burocracia e Robustez Informacional (50;15;85;15;15). A Burocracia estatal é avaliada em três controladores: Avesso (0 025 35); Indiferente (25 3565 75); e Propenso (65 75100 100). A Robustez informacional localiza diretrizes embasadas em estatísticas para os diferentes níveis (Educação Infantil, Fundamental, Ensino Médio, EJA e/ou Educação inclusiva, Técnica/Profissional, Superior/Pós), com os seguintes possíveis resultados: Básica, apresentando medidas estruturadas para até 3 dos níveis mencionados, Média para 4 níveis e, quando 5 ou 6 , Robusta.

O plano de Jair Bolsonaro, tal como o de João Amoedo, a partir da taxonomia apresentada, teve alto grau de pertencimento aos conjuntos eminentemente político e mormente político. O candidato, defensor de um projeto de Estado calcado no liberalismo econômico, tem como título "O Caminho para a Prosperidade". Inclui observações acerca de gastos (custo-efetividade), mas as diretrizes têm forte apelo à justiça social e estão vinculadas à proposição de uma mudança na base nacional comum curricular (BNCC). A educação à distância é importante instrumento, segundo o documento disponibilizado pelo candidato que concorreu pelo PSL, já que seria uma alternativa aos moradores de áreas rurais, por exemplo. As diretrizes, entretanto, não incluem maior detalhamento, no sentido de a estratégia vir acompanhada de alguma política pública de inclusão digital que a tornasse viável e efetivamente possível (BOLSONARO, 2018, p. 46). 
Coréia do Sul, China, Taiwan e a tática de parceria de Hélice Tripla são citadas, em um sentido de reprodução estratégica das políticas públicas implementadas por esses países (BOLSONARO, 2018, p. 41-49). As diretrizes sugerem estimular o desenvolvimento econômico a partir de uma ênfase aos cursos técnicos e "carreiras de exatas", além do estímulo ao empreendedorismo. Muito pouco foi discutido acerca da atuação e participação dos agentes professores, pais e comunidade na gestão escolar. Nenhum projeto específico (ainda que como proposição, como visto em outros planos) também citado para melhora do "péssimo desempenho educacional brasileiro".

$\mathrm{O}$ candidato do PSL foi o que demonstrou maior aversão ao aparato burocrático, incluindo, em vários momentos, sentenças como: "chega de carimbos, autorizações e burocracias, a complexidade burocrática alimenta a corrupção", "nas últimas décadas, o Governo Federal concentrou a arrecadação de tributos, criando burocracia e ineficiência para controlar os entes federados" [trechos do documento]. Das 81 páginas disponibilizadas, as que se dedicam às diretrizes educacionais representam cerca de 11\% (BOLSONARO, 2018, p. 41-49).

Figura 4 - Resultados fuzzy para a variável de entrada Viabilidade Técnica

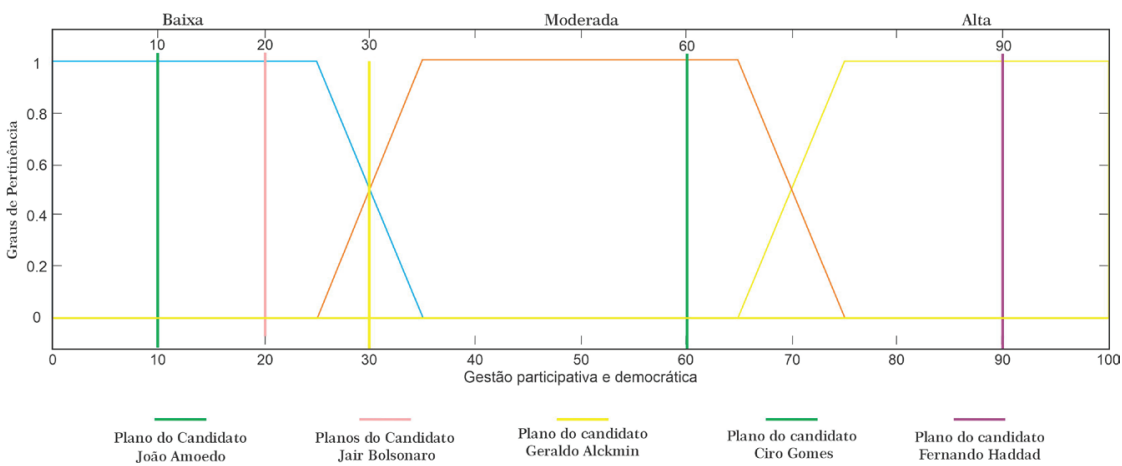

Fonte: Elaborada pelos autores a partir de informações coletadas dos planos de governo analisados.

Nota: A Figura 4 sintetiza os resultados associados à Viabilidade Técnica. A análise de conteúdo realizada com base no arcabouço teórico da seção anterior atribui os valores 20, 25, 50, 80 e 90 aos projetos dos candidatos João Amoedo, Jair Bolsonaro, Geraldo Alckmin, Ciro Gomes e Fernando Haddad, respectivamente. Visualiza-se que tais valores têm graus de pertencimento ou de pertinência 1,0 aos resultados. 
O "roteiro para o país voltar a crescer de Alckmin" dedicou dois tópicos à discussão das diretrizes ligadas à educação, ciência e tecnologia (ALCKIMIN, 2018, p. 14): das páginas 34-36 à Ciência, Tecnologia e Inovação (CT\&I) e das páginas 54 à 58, o documento apresenta diretrizes gerais para: (i) governança e financiamento; (ii) professor; (iii) primeira infância; (iv) alfabetização; (v) ensino médio; e (vi) ensino superior. Alckmin compunha a Coligação para Unir o Brasil e o resultado taxonômico de seu plano de governo mormente político é explicado pela ausência de detalhamento de estratégias e projetos que pudessem viabilizar a intencionalidade do Plano: "transformar a educação pública de qualidade no pilar central da igualdade de oportunidades e da qualificação dos jovens para o mercado de trabalho".

O projeto do candidato, apesar de não trazer estatísticas e informações mais técnicas para o critério de eficácia escolar, foi exitoso em demonstrar preocupação com a Pesquisa \& Desenvolvimento (P\&D), CT\&I e o Marco Legal de Ciência e Tecnologia, visando também ao estreitamento das relações entre a universidade e o setor produtivo. Propunha inclusive a instituição de um Sistema Brasileiro de Inovação para promover a modernização e a celeridade no sistema brasileiro de registro de patentes, via revitalização do Instituto Nacional da Propriedade Industrial (INPI). Um dos aspectos conflitantes das diretrizes do plano é o estímulo à meritocracia nas universidades e instituições públicas de pesquisa, realidade um tanto quanto controversa em um país com tantas assimetrias econômicas e sociais (ALCKMIN, 2018, p. 34-58).

$\mathrm{O}$ candidato do $\mathrm{PSDB}$ elencou o professor, junto à primeira infância e à juventude, como um dos três pilares de seu programa, tanto no que se refere à valorização quanto à reformulação da graduação, de forma a se adequar à prática. Pleiteava "assegurar a cobertura total da oferta de Educação Infantil de 4 e 5 anos com qualidade, garantindo a inclusão das 500 mil crianças nessa faixa etária que ainda estão fora da escola", além de "alfabetizar mães em situação de vulnerabilidade e jovens adultos de 15 a 29 anos" (ALCKMIN, 2018, p. 29). Para o Ensino Médio, as diretrizes de 
Alckmin previam - embora não apresentasse detalhamento estratégico ou evidências estatísticas para tal - redução de 50\% da evasão escolar e modernização da Lei do Aprendiz, de forma a facilitar a contratação dos jovens para o primeiro emprego.

Com graus de pertinência 1, e conforme explicita a Figura 5, as diretrizes de Bolsonaro e Amoedo foram alocadas no controlador Curto Prazo, enquanto as dos candidatos do PDT e PSDB, Médio Prazo. As proposições de Fernando Haddad apresentaram grau de pertencimento 1 para Longo Prazo. Esse critério leva em conta conteúdo de aprimoramento gradual, técnico e baseado em evidências, que possa pensar a trajetória do aluno desde o ensino infantil até a capacitação técnica e/ou pós-graduação, essenciais à geração de novas tecnologias e inovação.

Figura 5 - Resultados fuzzy para a variável de entrada Estratégia de Governo

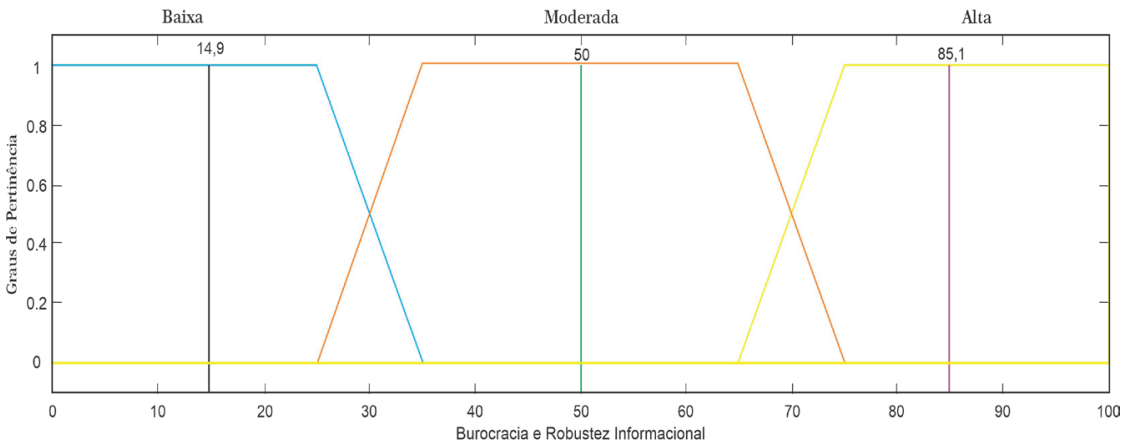

Planos dos candidatos médio e longo prazo, e os valores foram atribuídos a partir da noção imediatista ou não - nesse caso voltadas à um projeto de desenvolvimento - das sentenças das diretrizes.

O candidato do PDT propôs uma estratégia nacional de desenvolvimento, garantida pela qualificação obtida através de "boas políticas de educação" (GOMES, 2018, p. 4). As partes dedicadas à Educação, Ciência e Tecnologia foram especialmente 
compreendidas no quarto e no quinto tópicos, cerca de $11 \%$ do documento. Incluía em sua introdução, ajuste macroeconômico, que, segundo o Programa, equilibraria as finanças públicas e reduziria paulatinamente a participação de sua dívida no PIB do país. Propôs ainda a política de prêmio, trabalhada na literatura em textos como de Bonamino e Sousa (2012). A estratégia foi arriscada, já que passível de gerar efeitos negativos como o de treinamento para o simples cumprimento das metas e o perigo de um aumento irresponsável dos gastos do governo, já que não explicita melhor a forma pela qual o bônus seria financiado (GOMES, 2018, p. 26-32).

Pela proposta, seria constituído um "Novo Fundeb", pelo qual previa repasses da União de mais $10 \%$ em gastos discricionários, a depender da adesão das unidades da federação e municípios aos objetivos e princípios estipulados a nível federal. Também predizia o aumento dos gastos para municípios com indicadores de qualidade da educação mais baixos, na medida de diminuir as grandes disparidades entre escolas do país. Previa, ainda, a ampliação da rede de escolas para alfabetização de jovens e adultos (EJA), bem como cotas no Ensino Superior. O Plano do PDT não definia muito bem estratégias para a construção de uma gestão democrática/ participativa, o que explica o seu desempenho moderado nesse critério. Entretanto, fazia questão de apontar o fortalecimento do Conselho Nacional de Desenvolvimento Científico e Tecnológico (CNPq) e de instituições de pesquisa, como catalisadores de P\&D de inovações, relevantes dentro do critério Estratégia de Governo. 
Figura 6 - Resultados fuzzy para a variável de entrada Gestão Participativa e Democrática

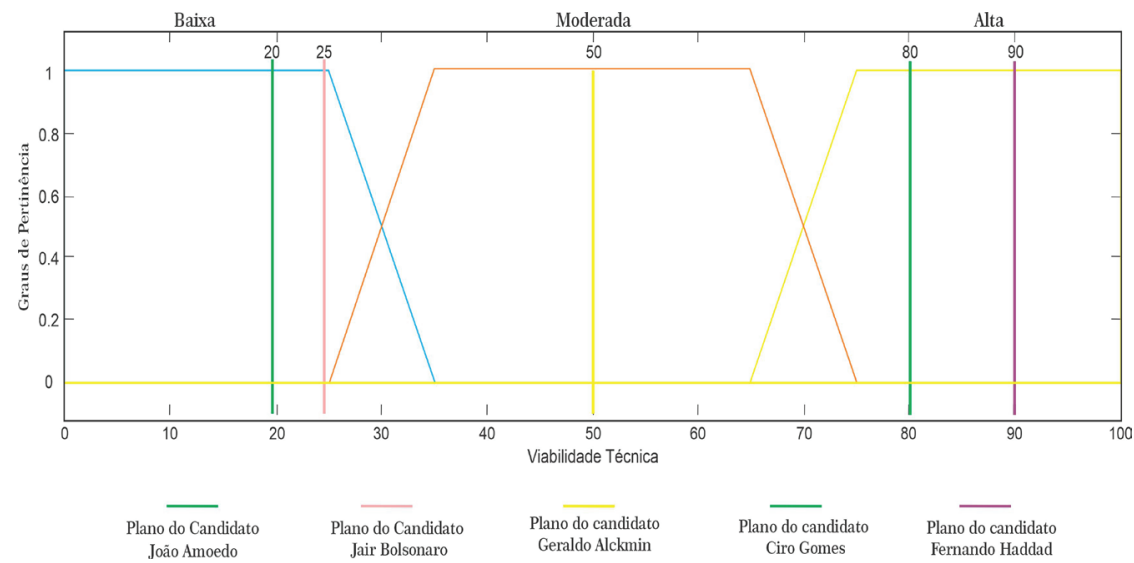

Fonte: Elaborada pelos autores a partir de informações coletadas dos planos de governo analisados.

Nota: As diretrizes para a variável de entrada Gestão Participativa e Democrática de João Amoedo, Jair Bolsonaro, Ciro Gomes e Fernando Haddad têm, respectivamente, os resultados 10,20,60 e 90, e graus de pertinência 1,0. 0 Plano do candidato Geraldo Alckmin (30) indica, conforme a Figura 6, grau de pertencimento 0,5 à variável linguística Baixa e 0,5 à Moderada.

Um dos pontos apresentados pelo candidato do PT à viabilidade de suas propostas para educação é a revogação da Emenda Constitucional n. 95, que fixa teto para o crescimento dos gastos públicos. Haddad propôs "criação de novo padrão de financiamento, objetivando, progressivamente, investir 10\% do PIB em educação, conforme a meta 20 do Plano Nacional da Educação (PNE); implementação do Custo-Aluno-Qualidade (QAQ) e institucionalização do novo Fundeb", utilizando parte dos royalties da estatal Petrobrás para garantir a viabilidade do projeto em termos de custo-efetividade.

Das diretrizes analisadas, foi o único candidato que incluiu textualmente a gestão democrática como estratégica, na seguinte forma: "gestão democrática, retomando o diálogo com a sociedade na gestão das políticas bem como na gestão das instituições escolares de todos os níveis" (HADDAD, 2018, p. 25). Prognosticou atenção à formação dos servidores escolares, por meio de novas ações e da retomada e ampliação do ProFuncionário e a organização de convênios com os Estados e o Distrito Federal para que o Governo Federal 
se responsabilize por escolas situadas em regiões de alta vulnerabilidade. Por meio do Plano Decenal de Ampliação dos Investimentos em CT\&I, previa um aumento da parcela do PIB em investimento em P\&D para $2 \%$ até 2030, porcentagem a qual o candidato do PSDB também elencou em seu Plano. Dos candidatos analisados, o ex-ministro da Educação foi o que se deteve nas diretrizes que mais se aproximavam do conjunto eminentemente político.

Dos cinco planos de governo, as diretrizes de Haddad se destacaram ao sugerirem o protagonismo de professores, diretores e comunidade acadêmica, embora a proposta carecesse de detalhamento maior acerca desse projeto de transformação dos "espaços públicos em polos de cultura, esporte e lazer". O plano de governo petista não excluiu a possibilidade de parcerias e apoio de entidades privadas que, de forma colaborativa, como no caso das políticas voltadas à C\&T, pudessem impactar positivamente em emprego, renda e bem-estar (HADDAD, 2018, p. 25-27). Tecemos, em seguida, algumas considerações e possíveis conclusões, abrindo uma janela para a ampliação e o aprofundamento dos esforços aqui auferidos.

\section{Considerações finais}

O argumento central de "Como as democracias morrem" (LEVITSKY; ZIBLATT, 2018) está alicerçado na ideia de que políticos extremistas já não utilizam as mesmas ferramentas golpistas vistas ao longo de todo o século XX. Segundo os autores, o Estado seria, a priori, capturado via processos "legais e democráticos" e, pouco a pouco, de dentro, os representantes corroeriam as instituições a fim de instaurar os seus projetos autocráticos. Uma estratégia nessa empreitada passaria, portanto, por um desmantelamento da educação pública, inclusive como um projeto de manutenção dos privilégios das elites (SOUZA, 2019). Nenhum país desenvolvido garantiu requisitos básicos de welfare state sem investir massivamente, de forma qualificada e a longo prazo em Ensino, Pesquisa e Tecnologia. Acende-se então um alerta no que se refere aos projetos, proposições e diretrizes para Educação apresentadas pela elite política brasileira na figura dos presidenciáveis. 
As mídias sociais vêm exercendo papel preponderante nos processos eleitorais dos últimos anos, especialmente por conta da popularização do acesso aos serviços de comunicação. Estatísticas demonstram que, no âmbito das eleições brasileiras de 2018, as mídias (canais abertos de televisão, rádios e jornais) foram os veículos com o segundo maior peso sobre a definição crítica de alternativas e agendas para o futuro pelos eleitores. Frente a esse contexto, as redes sociais foram massivamente empregadas como plataforma de campanha dos candidatos à presidência. Por meio de transmissões ao vivo (lives) em redes como YouTube, Facebook e Instagram, o eleitor pôde aproximar-se do posicionamento político de seu candidato e dos respectivos adversários, buscando entender as nuances de suas diretrizes de governo.

Contudo, a partir da análise de conteúdo realizada, as únicas diretrizes que dedicaram maior atenção ao critério de gestão democrática e participativa dos espaços educacionais foram apresentadas pelos candidatos Ciro Gomes (PDT) e Fernando Haddad (PT), os mesmos candidatos que, em seus planos, sugeriram maiores confiança e responsabilidade por parte do aparato burocrático nacional. Os planos dos demais candidatos analisados não pareceram acreditar na funcionalidade da burocracia vigente, sugerindo, ademais, que a simples desburocratização do sistema pudesse constituir-se em solução para grande parte das "ineficiências" do Estado brasileiro. As mesmas conclusões são válidas no tocante à ausência da inclusão da comunidade e efetivo protagonismo dos agentes (pais, professores, diretores, reitores servidores, alunos, entre outros) nas diretrizes gerais apresentadas por Jair Bolsonaro, Geraldo Alckmin e João Amoedo.

Os resultados obtidos na utilização da taxonomia para diretrizes de governo voltadas à Educação alertam para um cenário, no mínimo, desanimador, sob a perspectiva daqueles que vislumbram um futuro próximo no qual a Educação, a Pesquisa e a Ciência possam desempenhar protagonismo no desenvolvimento econômico brasileiro. Assumindo que tais proposições impactam diretamente na atuação governamental do candidato eventualmente 
eleito, é recomendado e urgente que a política nacional, na figura de seus candidatos em todas as esferas (municipal, estadual e federal), exerçam um tratamento de legítima responsabilidade dessa etapa da formação de agenda de políticas públicas, para que as eminentes desigualdades sociais, lato sensu, sejam atenuadas. A taxonomia proposta, inovadora em sua metodologia e multidisciplinar em sua base teórica, coloca uma lupa sobre as diretrizes apresentadas por políticos brasileiros, conteúdo por vezes negligenciado pelas ciências sociais.

Encerramos, aqui, as nossas considerações com um trade-off inesperado. As diretrizes dos candidatos que se aproximaram - ou mesmo, autodenominaram-se - de um espectro político à direita foram qualificadas como mormente e eminentemente políticas. Por sua vez, os candidatos que partiram do centro à esquerda tiveram proposições para Educação mormente e eminentemente técnicas. Embora essa distinção entre direita e esquerda na Ciência Política deva ser utilizada com ressalvas, como afirmado por Bobbio (1994) e outros, fato é que a fé embriagada (por parte dos que se identificam com a direita nacional) em cultuar o mercado ${ }^{18}$ parece ter forjado -não apenas no Brasil - discursos que naturalizam e reforçam múltiplas desigualdades. A fé (neo)liberal, a exemplo de países como Chile e Argentina, não se mostrara suficientemente eficaz nos últimos anos para garantir crescimento sustentado e desenvolvimento. Aos candidatos e atores políticos que compartilham o lado oposto da moeda, o grande desafio, dentro de um contexto globalizado de constante disseminação ora de informações, ora desinformações (fake news), é fazer com que o conteúdo técnico se torne mais palatável aos eleitores, que, por vezes, optam em privilegiar discursos e conteúdos vazios, os quais são historicamente manipulados pelas estruturas tradicionais de poder, como apontara Celso Furtado (1978) há mais de quatro décadas em Criatividade e Dependência na Civilização Industrial.

18 A partir de sua leitura de Polanyi, Evans (1995) explica que o mercado, sob essa ótica ortodoxa, é entendido como o solucionador de todos os problemas humanos, a partir de uma dada quantidade ilimitada de recursos monetários e financeiros. 


\section{Referências}

AGUM, Ricardo; RISCADO, Priscila; MENEZES, Monique. Políticas públicas: conceitos e análise em revisão. Agenda Política, [S. l.], v. 3, n. 2, p. 12-42, 2015.

ALVES, Maria Teresa Gonzaga; FRANCO, Creso. A pesquisa em eficácia escolar no Brasil: evidências sobre o efeito das escolas e fatores associados à eficácia escolar. In: BROOKE, Nigel; SOARES, José Francisco. (org.). Pesquisa em eficácia escolar: origem e trajetórias. Belo Horizonte: Editora UFMG, 2008. p. 482-500.

AMARAL, Oswaldo E. do; RIBEIRO, Pedro Floriano. Por que Dilma de novo? Uma análise exploratória do Estudo Eleitoral Brasileiro de 2014. Revista de Sociologia e Política, Curitiba, v. 23, n. 56, p. 107-123, dez. 2015.

ANDER-EGG, Ezequiel. Introducción a las técnicas de investigación social: para trabajadores sociales. 7. ed. Buenos Aires: Humanitas, 1978.

ANDRADE, Rogerio P. de. A construção do conceito de incerteza: uma comparação das contribuições de Knight, Keynes, Shackle e Davidson. Nova Economia, Belo Horizonte, v. 21, n. 2, p. 171-195, 2011.

ANTUNES, Jerônimo. Lógica nebulosa para avaliar riscos na auditoria. Revista Contabilidade \& Finanças, [Online], v. 17, n. especial, p. 80-91, 2006.

BACHRACH, Peter; BARATZ, Morton S. Duas FACES DO Poder. Revista Sociologia Política, Curitiba, v. 19, n. 40, p. 149-157, out. 2011.

BARDIN, Laurence. Análise de conteúdo. Lisboa: Edições 70, 1977.

BAUMGaRTNER, Frank R.; JONES, Bryan D. Agendas and instability in American politics. Chicago: University of Chicago Press, 1993.

BENINI, Luiz C. Uma introdução à teoria dos conjuntos fuzzy. In: CONGRESSO BRASILEIRO DE SISTEMAS "FUZZY", 2., nov. 2012, Natal. Anais [...]. Natal: SBMAC, 2012. 
BOBBIO, Norberto. Destra e sinistra. Ragioni e significati di una distinzione politica. Roma: Donzelli Editore, 1994.

BONAMINO, Alicia; SOUSA, Sandra Zákia. Três gerações de avaliação da educação básica no Brasil: interfaces com o currículo da/na escola. Educação e Pesquisa, São Paulo, v. 38, n. 2, p. 373-388, 2012.

BOZEMAN, Barry; PANDEY, Sanjay K. Public management decision making: effects of decision content. Public Administration Review, Washington, D. C., v. 64, n. 5, p. 553-565, 2004.

BRESSER-PEREIRA, Luiz Carlos. O conceito histórico de desenvolvimento econômico. São Paulo: FGV-EESP, dez. 2006. (Textos para discussão 157).

BROOKE, Nigel; SOARES, José Francisco. (org.). Pesquisa em eficácia escolar: origem e trajetórias. Belo Horizonte: Editora UFMG, 2008.

CARDOSO, Fernando Henrique; FALETTO, Enzo. Dependência e desenvolvimento na América Latina: um ensaio de interpretação sociológica. 5. ed. Rio de Janeiro: Zahar; 1979.

CASSIOLATO, José Eduardo. A economia do conhecimento e as novas políticas industriais e tecnológicas. In: LASTRES, Helena Maria Martins; ALBAGLI, Sarita (org.). Informação e globalização na era do conhecimento. Rio de Janeiro: Campus, 1999. p. 164-190.

DYE, Thomas D. Understanding public policy. Englewood Cliffs, N. J.: Prentice-Hall, 1984.

EDLER, Jakob; GEORGHIOU, Luke. Public procurement and innovation: resurrecting the demand side. Research Policy, [Online], v. 36, n. 7, p. 949-963, Sept. 2007.

EVANS, Peter B. Embedded autonomy: states and industrial transformation. Princeton: Princeton University Press, 1995.

FONSECA, Pedro Cezar Dutra. Desenvolvimentismo: a construção do conceito. In: DATHEIN, Ricardo(org.). Desenvolvimentismo: o conceito, as bases teóricas e as políticas. Porto Alegre: Editora da UFRGS, 2015. p. 13-71. 
FREEMAN, Chris. The "National System of Innovation" in historical perspective. Cambridge Journal of Economics, Oxford, v. 19, n. 1, p. 5-24, 1995.

FURTADO, Celso. Criatividade e dependência na civilização industrial. Rio de Janeiro: Paz e Terra, 1978.

FURTADO, Celso. Desenvolvimento e subdesenvolvimento. Rio de Janeiro: Fundo de Cultura, 1961.

GARCIA, Renato. Geografia da Inovação. In: RAPINI, Márcia Siqueira; SILVA, Leandro Alves; ALBUQUERQUE, Eduardo da Motta e. (org.) Economia da ciência, tecnologia e inovação: fundamentos teóricos e a economia global. Curitiba: Editora Prismas, 2017. p. 241-286.

GATTI, Bernadete Angelina. Formação de Professores no Brasil: características e problemas. Educação e Sociedade, Campinas, v. 31, n. 113, p. 1355-1379, out./dez. 2010.

GOMIDE, Alexandre; PIRES, Roberto. Capacidades estatais e democracia: a abordagem dos arranjos institucionais para análise de políticas públicas. In: GOMIDE, Alexandre; PIRES, Roberto. (org.). Capacidades estatais e democracia: arranjos institucionais de políticas públicas. Brasília: IPEA, 2014. p. 15-28. GOMIDE, Fernando Antonio Campos; GUDWIN, Ricardo Ribeiro. Modelagem, controle, sistema e lógica fuzzy. Controle e Automação, Campinas, v. 4, n. 3, p. 97-115, 1994.

HALL, Peter; TAYLOR, Rosemary C. R. As três versões do neo-institucionalismo. Lua Nova, [Online], n. 58, p. 193-223, 2003.

HAUSMAN, Daniel M; McPHERSON, Michael S. Economic analysis, moral philosophy and public policy. Cambridge: Cambridge University Press, 2006.

HUNTINGTON, Samuel P. Political order in changing societies.

New Haven: Yale University Press, 1968.

KINGDON, John W. Como chega a hora de uma ideia? In: SARAVIA, Enrique; FERRAREZI, Elisabete. (org.). Políticas públicas. Brasília: ENAP, 2006. p. 219-224. (Coletânea v. 1). 
LAZARETTI, Lauana Rossetto; TEIXEIRA, Felipe Orsolin; OLIVEIRA, Sibele Vasconcelosde.Desigualdadessocioeconômicas e demográficas nos municípios do Rio Grande do Sul/Brasil: um índice de vulnerabilidade à pobreza. Revista Brasileira de Gestão Urbana, [Online], v. 11, e20180154, 2019.

LEVITSKY, Steven; ZIBLATT, Daniel. Como as democracias morrem. Tradução de Renato Aguiar. Rio de Janeiro: Zahar, 2018. LINDBLOM, Charles Edward. The science of muddling through. Public Administration Review, Washington, D. C., v. 19, p. 79-88, 1959.

LOPEZ, Felix Garcia; PIRES, Roberto Rocha Coelho. Instituições participativas e políticas públicas no Brasil: características e evolução nas últimas duas décadas. In: INSTITUTO DE PESQUISA ECONÔMICA APLICADA. Brasil em Desenvolvimento: Estado, planejamento e políticas públicas. Brasília: IPEA, 2010. v. 3, p. 565-585.

MONT'ALVERNE, Camila; MITOZO, Isabele. Muito além da mamadeira erótica: as notícias compartilhadas nas redes de apoio a presidenciáveis em grupos de WhatsApp, nas eleições brasileiras de 2018. In: CONGRESSO DA ASSOCIAÇÃO BRASILEIRA DE PESQUISADORES EM COMUNICAÇÃO E POLÍTICA, 8., 15-17 maio 2019, Brasília. Anais [...]. Brasília: Compolítica, 2019. p. 1-25.

MORAES, Aline Cristina de Assis; RUIZ, Maria José Ferreira. A participação e a gestão democrática no programa nacional de fortalecimento dos conselhos escolares. Revista Eletrônica de Política e Gestão Educacional, [Online], n. 19, p. 212-226, 2017. MORAES, Roque. Análise de conteúdo. Revista Educação. Porto Alegre, v. 22, n. 37, p. 7-32, 1999.

MORTIMORE, Peter. School effectiveness research: which way at the cross-roads? School Effectiveness and School Improvement, [Online], v. 2, n. 3, p. 213-229, 1991.

MUZZI, Débora. Tipologia de políticas públicas: uma proposta de extensão do modelo de Lowi. 2014. Dissertação (Mestrado em Administração) - ISG - Escola de Gestão, Lisboa, 2014. 
NICOLAU, Jairo. Determinantes do voto no primeiro turno das eleições presidenciais brasileiras de 2010: uma análise exploratória. Opinião Pública, Campinas, v. 20, n. 3, p. 311-325, dez. 2014.

OLIVEIRA, Édivo de Almeida; CAIRES, Fernanda Oliveira; OLIVEIRA, Sibele Vasconcelos de. Uma análise exploratória para a identificação de clusters de propensão à criminalidade no estado da Bahia para o ano de 2010. Revista Econômica do Nordeste, Fortaleza, v. 48, n. 4, p. 9-24, out./dez. 2017.

OLIVEIRA et al. Análise do índice fuzzy de pobreza multidimensional em populações urbanas: um estudo de caso em Santa Maria (RS). Revista do CEPE, Santa Cruz do Sul, n. 47, p. 81-99, jan./jun. 2018. ORTEGA, Neli Regina Siqueira. Aplicação da teoria da lógica fuzzy a problemas de biomedicina. 2001. Tese (Doutorado em Ciências) - Instituto de Física, Universidade de São Paulo, São Paulo, 2001.

RAEDER, Savio Tulio Oselieri. Ciclo de políticas: uma abordagem integradora dos modelos para análise de políticas públicas. Perspectivas em Políticas Públicas. Belo Horizonte, v. VII, n. 13, p. 121-146, jan/jun. 2014.

RAGIN, Charles; PENNINGS, Paul. Fuzzy sets and social research. Sociological Methods \& Research, Thousand Oaks, v. 33, n. 4, p. 423-430, 2005.

SABATIER, Paul A.; WEIBLE, Christopher M. (ed.). Theories of the policy process. Boulder, C.O.: Westview Press, 1999.

SANTOS, Priscila Soares dos; OLIVEIRA, Sibele Vasconcelos de; DIAS, Lázaro Cézar. Análise de um índice fuzzy do potencial de aceitação social da política de ações afirmativas do Brasil (2017). In: ENCONTRO DE ECONOMIA DA REGIÃO SUL, 23., 2020, Porto Alegre. Anais [...]. Porto Alegre : ANPEC, 2020. Disponível em: https://www.anpec.org.br/sul/2020/submissao/ files_I/i2-faba7c5bb83bd7789a5856e3c7221410.pdf. Acesso em: 5 nov. 2020.

SECCHI, Leonardo. Políticas públicas: conceitos, esquemas de análise, casos práticos. São Paulo: Cengage Learning, 2014. SEN, Amartya. Desenvolvimento como liberdade. São Paulo: Companhia das Letras, 2013. 
SOARES, José Francisco; DELGADO, Victor Maia Senna. Medida das desigualdades de aprendizado entre estudantes de ensino fundamental. Revista Fundação Carlos Chagas, [Online], v. 27, n. 66, p. 754-780, 2016.

SOUZA, Celina. Políticas públicas: uma revisão da literatura. Sociologias, Porto Alegre, n 16, p. 20-45, 2006.

SOUZA, Jessé. A elite do atraso: da escravidão a Bolsonaro. Rio de Janeiro: GMT Editores, 2019.

VEBLEN, Thorstein. A teoria da classe ociosa: um estudo econômico das instituições. São Paulo: Abril Cultural, 1983. (Obra original publicada em 1912).

VONA, Francesco; CONSOLI, Davide. Innovation and skill dynamics: a life-cycle approach. Industrial and Corporate Change, Oxford, v. 24, n. 6, p. 1393-1415, Dec. 2015.

WEBER, Max; GERTH, Hans Heinrich; MILLS, Charles Wright.

From Max Weber: essays in sociology. Oxford: Oxford University Press, 1958.

ZADEH, Lotfi A. Fuzzy sets. Information and Control, [Online], v. 8, n. 3, p. 338-353, 1965.

ZUCOLOTO, Graziela Ferrero. Propriedade intelectual, origem de capital e desenvolvimento tecnológico: a experiência brasileira. Brasília: IPEA, mar. 2010. (Texto para Discussão n. 1.475). Disponível em: http://goo.gl/A2PxY9. Acesso em: 14 mar. 2021.

\section{Programas de governo da eleição presidencial de 2018 citados}

ALCKMIN, Geraldo. Diretrizes gerais: julho 2018. Disponível em: http://divulgacandcontas.tse.jus.br/candidaturas/oficial/2018/ BR/BR/2022802018/280000602477/proposta_1533849607885. pdf. Acesso em: 23 jan. 2020.

AMOEDO, João.Programadegoverno2019/2022: Maisoportunidades menos privilégios. Disponível em: http://divulgacandcontas.tse.jus. br/candidaturas/oficial/2018/BR/BR/2022802018/280000607640/ proposta_1534522080782.pdf. Acesso em: 23 jan. 2020. 
BOLSONARO, Jair Messias. Proposta deplano degoverno: ocaminho da prosperidade. Disponível em: http://divulgacandcontas.tse.jus. br/candidaturas/oficial/2018/BR/BR/2022802018/280000614517/ proposta_1534284632231.pdf. Acesso em: 23 jan. 2020.

GOMES, Ciro. Diretrizes para uma estratégia nacional de desenvolvimento para o Brasil. Disponível em: http:// divulgacandcontas.tse.jus.br/candidaturas/oficial/2018/BR/ BR/2022802018/280000605589/proposta_1533938913830.pdf. Acesso em: 23 jan. 2020.

HADDAD, Fernando. Plano de governo 2019-2022: coligação "O povofelizdenovo". Disponívelem:http://divulgacandcontas.tse.jus. br/candidaturas/oficial/2018/BR/BR/2022802018/280000629808/ proposta_1536702143353.pdf. Acesso em: 23 jan. 2020.

\section{Resumo}

Compreendendo a importância da política e da participação pública no fortalecimento e legitimidade de estados democráticos, o artigo tem por objetivo analisar as diretrizes para educação dos planos de governo dos cinco candidatos mais votados na eleição presidencial brasileira em 2018. O uso da metodologia fuzzy é justificado pela grande aplicabilidade do método nas áreas das ciências sociais, sendo capaz de mapear quali e quantitativamente as informações e detalhamento das propostas. Sugere-se uma taxonomia, a qual dá um passo adiante em comparação à tradicional lógica booleana. Ressaltam-se como resultados: (i) preponderantemente, as diretrizes analisadas estão contidas em conjuntos mormente e eminentemente políticos; (ii) apenas dois candidatos dedicaram-se mais ao critério "Gestão democrática e participativa dos espaços educacionais"; (iii) proposições de candidatos que se aproximam de um espectro político à direita foram qualificadas como mormente e/ ou eminentemente políticas e as de candidatos que se aproximam da esquerda, mormente e/ou eminentemente técnicas. Assumindo que tais propostas impactam diretamente na atuação governamental, é urgente e recomendado que os elegíveis exerçam um tratamento legítimo e responsável dessa etapa da formação de agenda de políticas públicas para que as desigualdades sociais, lato sensu, sejam atenuadas ao longo das próximas décadas.

Palavras-chave: Eleição presidencial. Políticas públicas. Sistema fuzzy. 


\section{Abstract}

Given the importance of politics and public participation in the strengthening and legitimacy of democratic states, this paper intends to analyze the government agenda setting guidelines for education of the five most-voted candidates in the Brazilian presidential election in 2018. The use of the fuzzy methodology is justified by the method's great applicability of the method for the social sciences, considering its capacity to map, qualitatively and quantitatively, the information and details of the proposals. A taxonomy is suggested, taking a step beyond Boolean logic. We highlight as results: (i) the analyzed guidelines are predominantly contained in eminently political sets; (ii) only two candidates paid more attention to the democratic and participative management of educational spaces; (iii) the governing programs of candidates who approached the right of the political spectrum were qualified as mainly and/or eminently political and, candidates who approached the left had mainly and eminently technical proposals for education. Assuming that such proposals have a direct impact on government action, it is urgent and recommended that Brazilian politicians undertake legitimate and responsible treatment of this stage of the public policy agenda, so that social inequalities, lato sensu, are mitigated in the coming decades.

Keywords: Presidential election. Public policies. Fuzzy set.

Recebido em 07 de julho de 2020;

Aceito em 09 de fevereiro de 2021.

\section{ERRATA: Taxonomia das diretrizes para educação nos planos de governo dos elegíveis à Presidência da República Brasileira (2018)}

No artigo “Taxonomia das diretrizes para educação nos planos de governo dos elegíveis à Presidência da República Brasileira (2018)", com número de DOI: https://doi.org/10.1590/01033352.2021.35.240636, publicado no periódico "Revista Brasileira de Ciência Política”, n. 35, 2021, p. 1-38,

os títulos "Figura 3 - Resultados fuzzy para a variável de entrada Burocracia e Robustez Informacional", "Figura 4 - Resultados fuzzy para a variável de entrada Viabilidade Técnica", "Figura 5 - Resultados fuzzy para a variável de entrada Estratégia de Governo", e 
"Figura 6 - Resultados fuzzy para a variável de entrada Gestão Participativa e Democrática” não correspondem às imagens que vêm em seguida.

Na página 22:

"A imagem da página 22 corresponde à Figura 5 - Resultados fuzzy para a variável de entrada Estratégia de Governo."

Onde se lia:

"Figura 3 - Resultados fuzzy para a variável de entrada Burocracia e Robustez Informacional

Nota: No primeiro nível, a análise de conteúdo atribui os seguintes valores para as variáveis de entrada (Burocracia; Robustez informacional): Ciro Gomes (50;4), Jair Bolsonaro (10;4), Fernando Haddad (60;6), João Amoedo (20;3) e Geraldo Alckmin (20;0). Fazendo uso do MATLAB, e para cada um dos respectivos candidatos, obtiveram-se os outputs para o critério Burocracia e Robustez Informacional $(50 ; 15 ; 85 ; 15 ; 15)$. A Burocracia estatal é avaliada em três controladores: Avesso (0 025 35); Indiferente (25 3565 75); e Propenso (65 75100 100). A Robustez informacional localiza diretrizes embasadas em estatísticas para os diferentes níveis (Educação Infantil, Fundamental, Ensino Médio, EJA e/ou Educação inclusiva, Técnica/Profissional, Superior/Pós), com os seguintes possíveis resultados: Básica, apresentando medidas estruturadas para até 3 dos níveis mencionados, Média para 4 níveis e, quando 5 ou 6, Robusta."

Leia-se:

"Figura 3 - Resultados fuzzy para a variável de entrada Estratégia de Governo

Nota: A variável de entrada Estratégia de Governo é pensada em um período de 0 a 30 anos, alternando, de forma crescente, curto, médio e longo prazo, e os valores foram atribuídos a partir da noção 
imediatista ou não - nesse caso voltadas à um projeto de desenvolvimento - das sentenças das diretrizes."

Na página 23:

"A imagem da página 23 corresponde à Figura 6 - Resultados fuzzy para a variável de entrada Gestão Participativa e Democrática.”

Onde se lia:

\section{"Figura 4 - Resultados fuzzy para a variável de entrada Viabi- lidade Técnica}

Nota: A Figura 4 sintetiza os resultados associados à Viabilidade Técnica. A análise de conteúdo realizada com base no arcabouço teórico da seção anterior atribui os valores 20, 25, 50, 80 e 90 aos projetos dos candidatos João Amoedo, Jair Bolsonaro, Geraldo Alckmin, Ciro Gomes e Fernando Haddad, respectivamente. Visualiza-se que tais valores têm graus de pertencimento ou de pertinência 1,0 aos resultados."

\section{Leia-se:}

“Figura 4 - Resultados fuzzy para a variável de entrada Gestão Participativa e Democrática

Nota: As diretrizes para a variável de entrada Gestão Participativa e Democrática de João Amoedo, Jair Bolsonaro, Ciro Gomes e Fernando Haddad têm, respectivamente, os resultados 10, 20, 60 e 90, e graus de pertinência 1,0. O Plano do candidato Geraldo Alckmin (30) indica, conforme a Figura 6, grau de pertencimento 0,5 à variável linguística Baixa e 0,5 à Moderada."

Na página 25:

"A imagem da página 25 corresponde à "Figura 3 - Resultados fuzzy para a variável de entrada Burocracia e Robustez Informacional” 
Onde se lia:

\section{"Figura 5 - Resultados fuzzy para a variável de entrada Estra- tégia de Governo}

Nota: A variável de entrada Estratégia de Governo é pensada em um período de 0 a 30 anos, alternando, de forma crescente, curto, médio e longo prazo, e os valores foram atribuídos a partir da noção imediatista ou não - nesse caso voltadas à um projeto de desenvolvimento - das sentenças das diretrizes."

Leia-se:

“Figura 5 - Resultados fuzzy para a variável de entrada Burocracia e Robustez Informacional

Nota: No primeiro nível, a análise de conteúdo atribui os seguintes valores para as variáveis de entrada (Burocracia; Robustez informacional): Ciro Gomes (50;4), Jair Bolsonaro (10;4), Fernando Haddad $(60 ; 6)$, João Amoedo (20;3) e Geraldo Alckmin (20;0). Fazendo uso do MATLAB, e para cada um dos respectivos candidatos, obtiveram-se os outputs para o critério Burocracia e Robustez Informacional $(50 ; 15 ; 85 ; 15 ; 15)$. A Burocracia estatal é avaliada em três controladores: Avesso (0 025 35); Indiferente (25 3565 75); e Propenso (65 75 100 100). A Robustez informacional localiza diretrizes embasadas em estatísticas para os diferentes níveis (Educação Infantil, Fundamental, Ensino Médio, EJA e/ou Educação inclusiva, Técnica/Profissional, Superior/Pós), com os seguintes possíveis resultados: Básica, apresentando medidas estruturadas para até 3 dos níveis mencionados, Média para 4 níveis e, quando 5 ou 6, Robusta."

Na página 27:

"A imagem da página 27 corresponde à "Figura 4 - Resultados fuzzy para a variável de entrada Viabilidade Técnica."

Onde se lia:

"Figura 6 - Resultados fuzzy para a variável de entrada Gestão Participativa e Democrática 
Nota: As diretrizes para a variável de entrada Gestão Participativa e Democrática de João Amoedo, Jair Bolsonaro, Ciro Gomes e Fernando Haddad têm, respectivamente, os resultados 10, 20, 60 e 90, e graus de pertinência 1,0. O Plano do candidato Geraldo Alckmin (30) indica, conforme a Figura 6, grau de pertencimento 0,5 à variável linguística Baixa e 0,5 à Moderada.”

Leia-se:

"Figura 6 - Resultados fuzzy para a variável de entrada Viabilidade Técnica

Nota: A Figura 4 sintetiza os resultados associados à Viabilidade Técnica. A análise de conteúdo realizada com base no arcabouço teórico da seção anterior atribui os valores 20, 25, 50, 80 e 90 aos projetos dos candidatos João Amoedo, Jair Bolsonaro, Geraldo Alckmin, Ciro Gomes e Fernando Haddad, respectivamente. Visualiza-se que tais valores têm graus de pertencimento ou de pertinência 1,0 aos resultados.” 